\title{
The Behaviour of Blind-Bolted Open Sections to Hollow Sections Moment Connections under Static Loading
}

\author{
Abdelrahman M. Fahmy \\ Department of Structural Engineering, Ain Shams University, El Abbassia, Cairo, Egypt \\ E-mail: a.mohamedfahmi@gmail.com
}

Associate Prof. Dr. Said Y. Aboul Haggag

Department of Structural Engineering, Ain Shams University, El Abbassia, Cairo, Egypt

E-mail: said_haggag@eng.asu.edu.eg

Prof. Dr. Abdelrahim K. Dessouki

Department of Structural Engineering, Ain Shams University, El Abbassia, Cairo, Egypt

E-mail: dessouki_ceo@hotmail.com

Received: 24 Oct. 2019 / Accepted 22 Dec. 2019 / Publication date: 15 Jan. 2020

\begin{abstract}
There are many advantages reported as a result of the combination of an open I section connection to a hollow tubular section column. Architects find it useful in many occasions to use structural hollow sections in multi-story constructions, because of their high strength to weight ratio. These connections are easy, with fast installation, fine shape, and simple constitution without the need for field welding. Bolting to the face of the tube is considered one of the remaining areas of difficulty regarding the use of structural hollow sections. Tightening a standard bolt and nut is difficult especially when the walls of hollow sections are relatively thin and welding is not efficient. Recent developments in bolting technology have developed a system that overcomes the complexity involved in the connection between open and hollow sections; Blind-bolting connection. Currently, the main usage of the blind-bolting is shear connections, whereas rigid behaviour may be achieved by fully welded connection. The most famous available blind bolts include BoxBolt, Flowdrill, Huck high strength blind-bolt, Ajax blind bolt, and Lindapter Hollobolt. The aim of this paper is to study the behaviour of open section bolted connections to tubular members under static loading using end plates, to find forces in bolts and their force distribution, the failure modes of the bolts and the end plate.
\end{abstract}

Keywords: Endplate connections, Blind bolts, Blind connections, Hollow sections, Metal forming.

\section{Introduction}

The use of tubular sections in low rise structures has traditionally been avoided by access constraints to provide for a fully bolted connection. This is now solved by using a blind bolting connection which requires access to one side only. The most famous types of blind bolted moment connections are the extended - end plate connections and the T-stub connections which are fixed to the outer face of the tube column, also referred to herein as face connections. Latest studies done by Lee et al. (2010) show that the increase in endplate thickness for a typical T-stub connection can improve the stiffness of the blind bolted connection. However, this is only true till a certain endplate thickness beyond which the stiffness of the connection is governed by the flexibility of the tube column. The flexibility of the square hollow section (SHS) column face renders the face connection semi-rigid. Early investigations of framing connections between I-beams and SHS were carried out by White and Fang (1966). Five different types of simple connections between I-section and SHS were tested. White and Fang (1966) found that the large deformation of the column face would reduce the stiffness of the sub-assemblage significantly. A suggestion was introduced which is to concentrate welding near the corners of the hollow tubular section to avoid excessive deformations and enhancing the stiffness of the blind connection.

Groux and Picard (1977) built on the concept of transferring loads from the I-beams close to the corners of SHS columns to prevent excessive column face deformation. They developed the coped 
strap angle connection which connects I-beams to the sides of an SHS column. It was found that the strap angle connection was not as stiff as a full butt -welded connection between I-beams and SHS columns but the connection had considerable stiffness and was able to carry the full plastic moment of the connecting beams with adequate rotation capacity. Rao et al. (2006) developed an SHS beam to column connection. The SHS beam was bolted to a channel and the channel was welded to the sides of the SHS column. As blind bolts were not used in this connection, a web opening was introduced to provide access to tighten the nut of a conventional bolt inside the SHS beam. This highlights the convenience of using blind bolts. The channel connectors transferred stresses from the beam flanges to the column webs directly. The connection was totally independent of the column face thus avoiding flexible column face deformation. Even though connecting to the sides of the SHS has the added advantage of increasing the strength and stiffness of the connection, there are no such standard connections developed or in use in current practice.

Wang and Zhang, (2017), investigated the performance of circular concrete filled steel tubular (CFST) column to steel beam joints with blind bolts. Four monotonic loading tests were conducted on the flush or extended end plate joints to circular CFST columns with blind bolts. A nonlinear finite element (FE) modelling study on the circular CFST column joints under static loading was developed considering contact interaction, material model and analysis steps. Wang, and Wang, (2016), evaluated the yield and ultimate strengths of a blind bolted endplate to square tubular column connection in joint tensile region. It outlines a research work of eleven connection tests with focus on the strengths of the connection components under tensile loads. The influences of the bolt gauge width, slenderness of tubular columns and bolt size details on the strengths of the connections in three failure modes are reported. Based on the experimental test results, yield strength determination methods are examined and discussed on the basis of deformations of the tube connecting face and the overall connection.

This paper studies the feasibility of connecting to the sides of an SHS with blind bolts as an alternative to the T-stub or extended end plate connection in order to achieve a connection with a higher stiffness compared to typical face connections. In addition to typical strength requirements, these connections shall take into consideration the below factors:

a) The toughness of the joining elements in the connections, including welds.

b) High level of understanding of the distribution of stresses and strains of the connection.

c) Removing any stress concentrations.

d) Detailed consideration of the flow of forces and the expected path of yield line in the connection.

e) Good understanding of the properties of the materials of the connection.

f) The need for high quality control in fabrication, erection, and inspection of the blind bolted connection.

\section{Analytical Modelling Setup}

\section{Overall View of the Tested Connections}

A parametric study has been established to investigate the effect of various parameters on the blind bolted connection. The connection used is from paper by Tizani et al., (2013).

The connections consisted of open I section connected to a square hollow section by various numbers of bolts while the end plate is fully penetrated to I section as shown in figure 1 .

The purpose of the analytical model is to check the different failure modes of the connection under static load. Figure 2 shows the theoretical rotation of the connection versus the analytical rotation which gives the same behaviour as per previous experimental tests by Wang and Spencer Jr., (2013).

\section{Obstacles in performing the finite model}

The main obstacle in this connection is to simulate the blind bolt correctly and ensure the contact between the sleeve (when it opens) and the inner face of the supporting square hollow sections. Figure 3 shows the real Hollobolt versus the applied bolt in the analytical model taking into consideration that the sleeve is opened with a specific angle to make sure that it is in contact with the inner face of the square hollow section. A lindapter hollow bolt is used in the study; refer to Lindapter, (2011), technical innovation in steel construction for blind bolting connection. 
Blind bolt $\rightarrow$
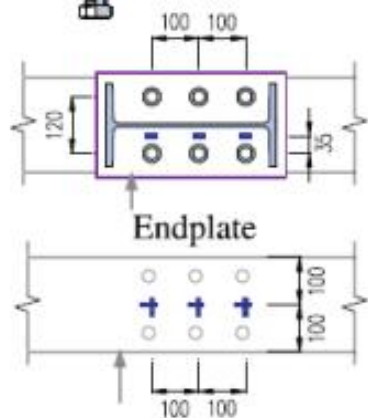

$\underline{\text { Section A-A }}$

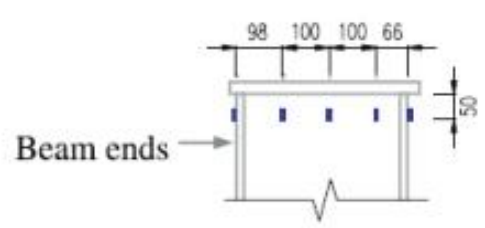

Fig. 1: Connection setup and fixation details
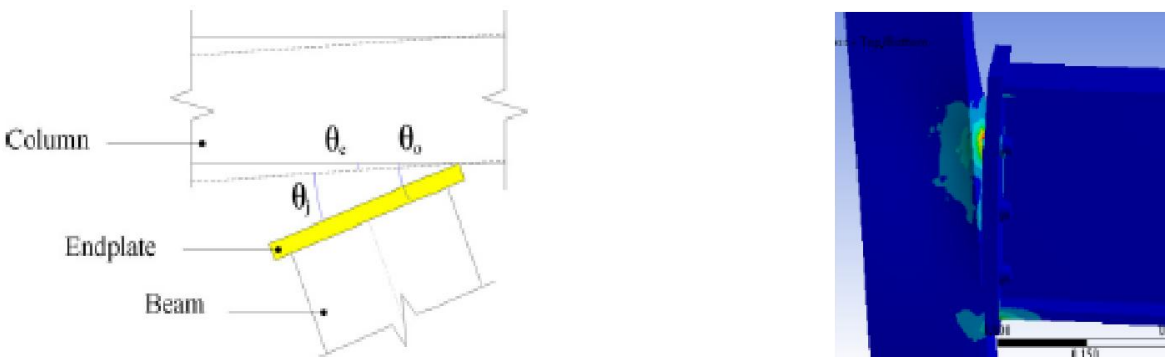

Fig. 2: Theoretical rotation versus analytical rotation
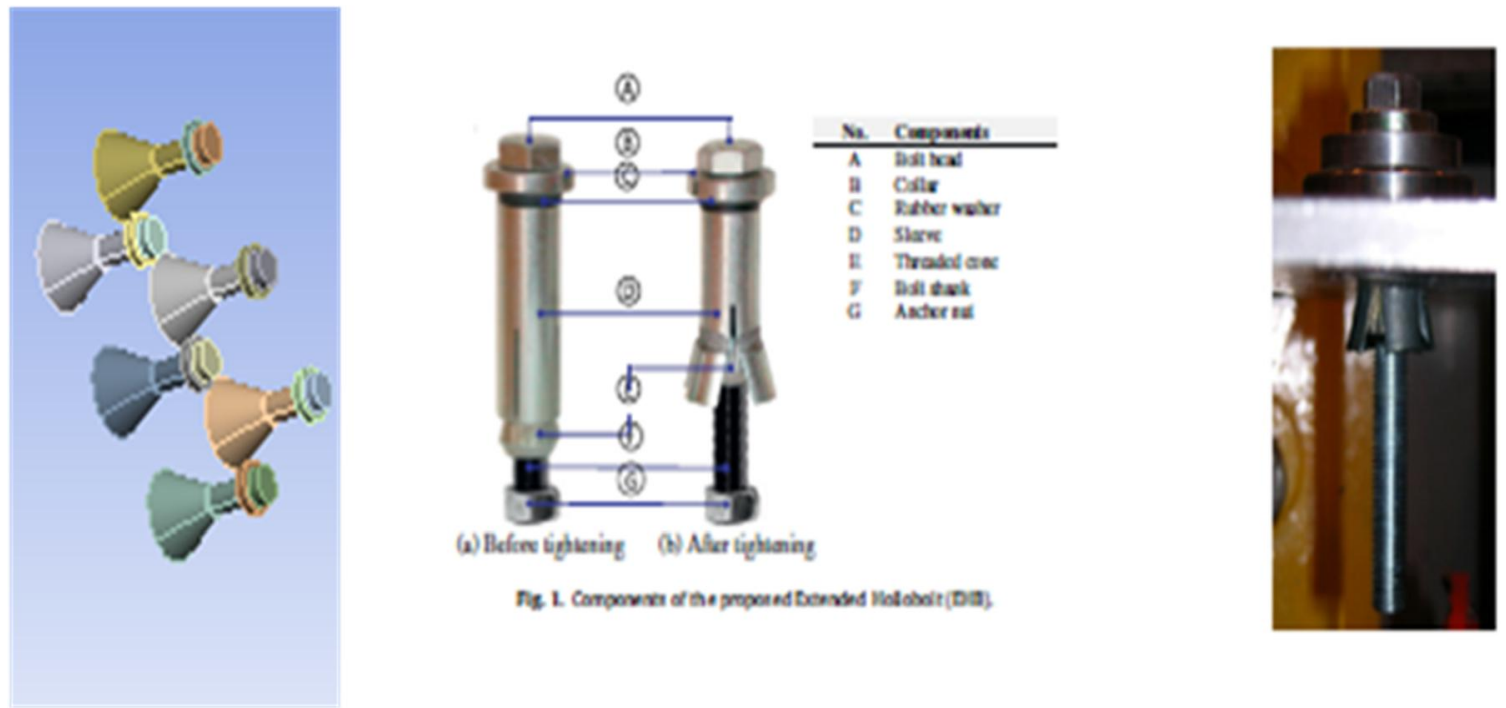

Fig. 3: Blind bolt used in the analytical model versus the real bolts used in experimental tests 


\section{Static loading procedure}

Static loading is applied on the connection with gradual increase in the force until the failure of the connection. Figure 4 shows the force acting at the end of the beam. The applied force induces a bending moment on the connection while restraining the lateral torsional buckling of the beam. The column is simulated to be fixed at both ends as a simulation that the column is linked to a slab in both ends which is rigid enough, Wang and Zhang, (2017). The sleeve is opened with 15 degree with the vertical, Brian and Patel, (2015), or the suitable angle according to the connection configuration to simulate the actual behaviour of the connection after tightening as the connection will not work unless the sleeve opens and there is a contact between the sleeve outer face and the inner face of the column.

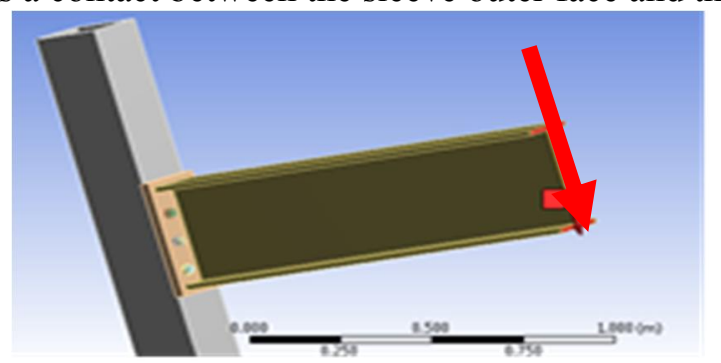

Fig. 4: Application of static force on the connection

\section{Finite Element Models}

\section{Models}

Finite element models have been established to study the effect of various parameters on the connection. Tube thickness, steel grade and bolt grade are the parameters included in the study. It is predicted that the failure will be in the sleeve or the hole in the square tube thickness which will enlarge till it is wide enough for the bolt to pass through and which will be considered as a sudden brittle failure. Table 1 shows the studied connections and detailed data for all connection material specification items.

Table 1: Finite models to show the effect of various parameters on the connection

\begin{tabular}{|c|c|c|c|c|c|c|c|c|c|}
\hline Model & $\begin{array}{l}\text { Beam } \\
\text { grade } \\
\text { (MPa) }\end{array}$ & $\begin{array}{l}\text { Sleeve } \\
\text { grade } \\
\text { (MPa) }\end{array}$ & $\begin{array}{c}\text { Tube } \\
\text { grade } \\
\text { (MPa) }\end{array}$ & $\begin{array}{l}\text { Plate } \\
\text { grade } \\
\text { (MPa) }\end{array}$ & $\begin{array}{c}\text { Tube } \\
\text { thickness } \\
(\mathrm{mm})\end{array}$ & $\begin{array}{c}\text { Bolt } \\
\text { grade } \\
(\mathrm{mm})\end{array}$ & $\begin{array}{c}\text { Bolt } \\
\text { diameter } \\
(\mathbf{m m})\end{array}$ & $\begin{array}{c}\text { End } \\
\text { plate } \\
\text { thickness } \\
(\mathrm{mm})\end{array}$ & $\begin{array}{c}\text { Sleeve } \\
\text { thickness } \\
(\mathrm{mm})\end{array}$ \\
\hline 1 & 355 & 235 & 355 & 355 & 12 & 10.9 & 20 & 25 & 6 \\
\hline 2 & 355 & 235 & 355 & 355 & 12 & 10.9 & 20 & 25 & 7 \\
\hline 3 & 355 & 235 & 355 & 355 & 12 & 10.9 & 20 & 25 & 8 \\
\hline 4 & 355 & 355 & 235 & 355 & 8 & 10.9 & 16 & 25 & 8 \\
\hline 5 & 355 & 355 & 235 & 355 & 10 & 10.9 & 16 & 25 & 8 \\
\hline 6 & 355 & 355 & 235 & 355 & 12 & 10.9 & 16 & 25 & 8 \\
\hline 7 & 355 & 355 & 355 & 235 & 8 & 10.9 & 16 & 15 & 8 \\
\hline 8 & 355 & 355 & 355 & 235 & 8 & 10.9 & 16 & 20 & 8 \\
\hline 9 & 355 & 355 & 355 & 235 & 8 & 10.9 & 16 & 25 & 8 \\
\hline 10 & 355 & 355 & 355 & 355 & 12 & 8.8 & 22 & 25 & 8 \\
\hline 11 & 355 & 355 & 355 & 355 & 12 & 8.8 & 16 & 25 & 8 \\
\hline 12 & 355 & 355 & 355 & 355 & 12 & 8.8 & 20 & 25 & 8 \\
\hline 13 & 355 & 355 & 355 & 355 & 8 & 10.9 & 16 & 25 & 8 \\
\hline 14 & 355 & 355 & 355 & 355 & 12 & 10.9 & 22 & 25 & 8 \\
\hline 15 & 355 & 355 & 355 & 355 & 12 & 10.9 & 20 & 25 & 6 \\
\hline
\end{tabular}

\section{Materials specification}

The tube, the end plate, the beam and sleeve materials are considered as shown in table 1 in the analysis and introduced in the finite model based on Mashaly et al., (2011). Approximate stress-strain curve for both steel elements and bolts as shown in Figure 5 to simulate the exact stress strain curve used in the analysis models which is difficult to use in analytical models. 


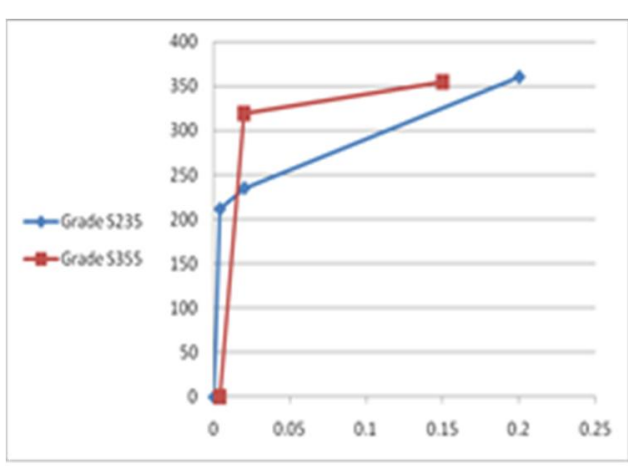

a) For steel sections

Fig. 5: Trilinear stress strain curve

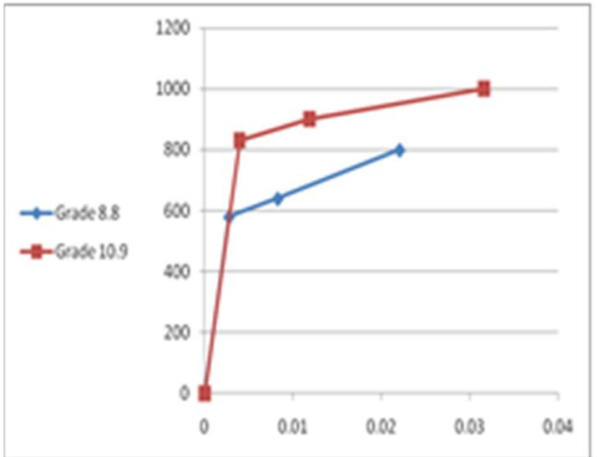

b) For high strength bolts

Tables 2 and 3 shows the used yield, proof, and ultimate stresses for each grade of steel elements as per DNV-RP-C208, (2013).

According to Mashaly et al. (2011), the yield, proof and ultimate stress of the elements shall be provided to be able to draw a stress strain curve for any material with any grade. According to ISO 898-1, table 4 is provided specifying all the above mentioned stresses for bolt grades.

Table 2: Proposed non-linear properties for S235 steels (Engineering stress-strain)

\begin{tabular}{llll}
\hline Material & & S235 & $40 \leq \mathrm{t} \leq 63$ \\
\hline Thickness [mm] & $\mathrm{t} \leq 16$ & $16 \leq \mathrm{t} \leq 40$ & \\
E [MPa] & & 210000 & \\
Prop/ Yield & & 0.9 & 193.5 \\
Ep $/$ E & 211.5 & 0.001 & 215 \\
Prop [MPa] & 235 & 202.5 & 218.4 \\
Yield [MPa] & 238.4 & 225 & 360 \\
Yield2 [MPa] & 360 & 228.4 & 360 \\
Ult [MPa] & & 360 & \\
\hline
\end{tabular}

Table 3: Proposed non-linear properties for S355 steels (Engineering stress-strain)

\begin{tabular}{llll}
\hline Material & & S355 & \\
\cline { 1 - 2 } Thickness [mm] & $\mathrm{t} \leq 16$ & $16 \leq \mathrm{t} \leq 40$ & \\
E [MPa] & & 210000 & \\
Prop/ Yield & & 0.9 & \\
E1 $/$ E & 378 & 0.001 & 351 \\
Prop [MPa] & 420 & 360 & 390 \\
Yield [MPa] & 421.3 & 400 & 391.3 \\
Yield2 [MPa] & 500 & 401.3 & 480 \\
Ult [MPa] & 500 & \\
\hline
\end{tabular}

Table 4: Mechanical and physical properties of bolts

\begin{tabular}{lccc}
\hline Mechanical or physical property & \multicolumn{2}{c}{$\mathbf{1 0 . 9}$} \\
\hline & d less than or & d more than \\
& equal $16 \mathrm{~mm}$ & $16 \mathrm{~mm}$ & 1000 \\
Tensile strength, $\mathbf{R}_{\mathbf{m}}, \mathbf{M P a}$ & 800 & 830 & 900 \\
Stress at $\mathbf{0 . 2} \%$ non-proportional elongation, $\mathbf{R p}_{\mathbf{0 . 2}}$, & 640 & 640 & 830 \\
MPa & & & 600 \\
Stress under proof load, $\mathbf{S}_{\mathbf{f}}, \mathbf{M P a}$ & 580 & & \\
\hline
\end{tabular}

\section{Meshing}

Meshing is applied to all solid and areas to ensure the proper preview of the stress distribution and ensuring that all elements are connected together. ANSYS workbench 15.0 has a very unique option, the meshing of each element can work together homogenously even if the meshing is not connected which is a very useful feature. Figure 6 shows how the connection is meshed 
homogenously and working together to provide the perfect stress distribution for all elements and ensure proper behaviour of the connection.

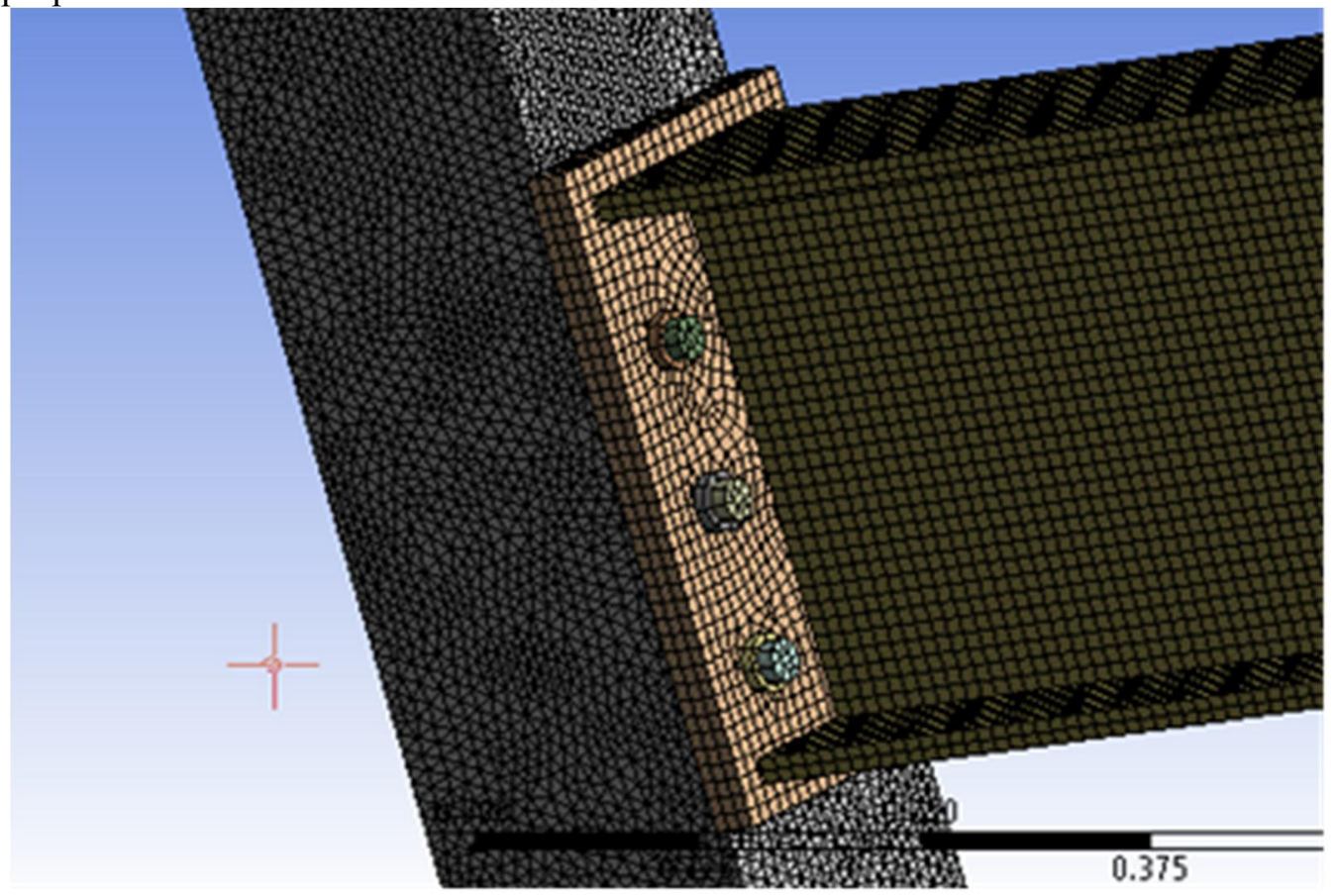

Fig. 6: Meshing of the overall connection

\section{Contact between different elements in the connection}

The only way the connection works efficiently as one unit is that each part in it is connected to one another in a homogenous way to allow for proper propagation of the load all through the connection. Table 5 illustrates different contacts between connection elements and their type. Contacts are classified into different types; bonded, frictionless, no separation, rough, and frictional.

Table 5: Contact area classification between all connection elements
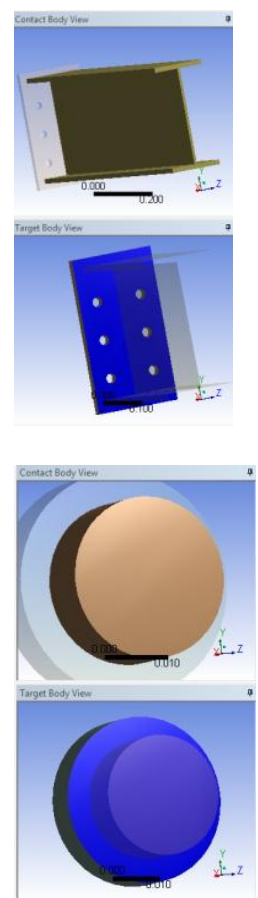

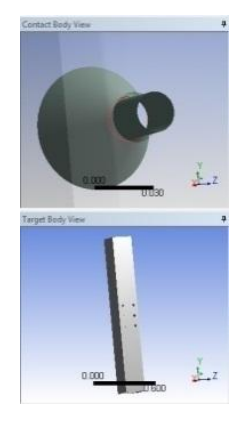

Bonded
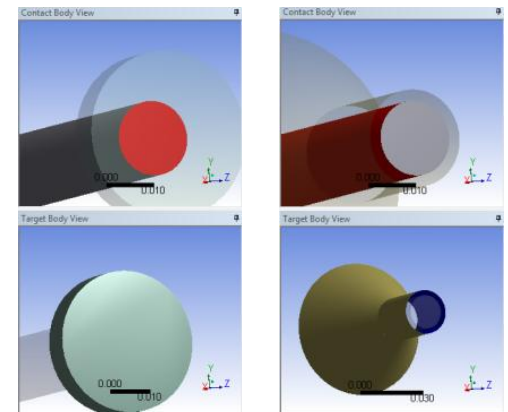
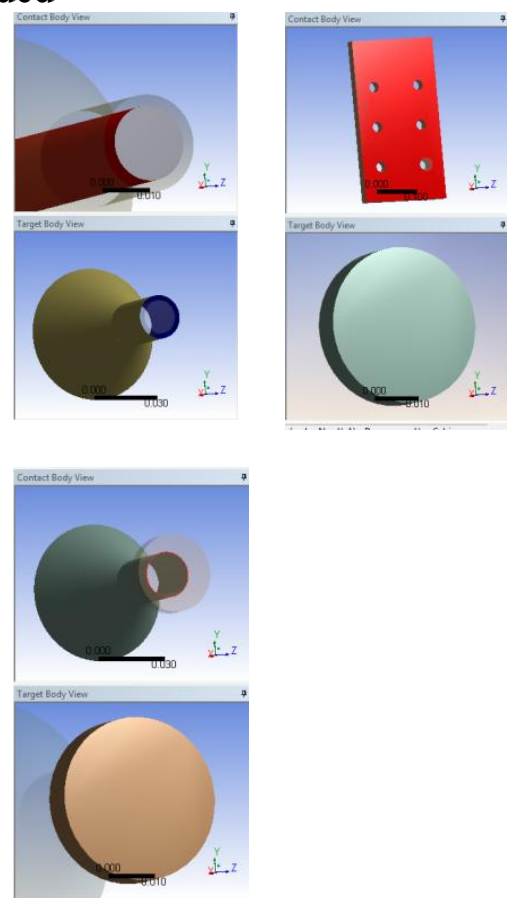

Frictionless
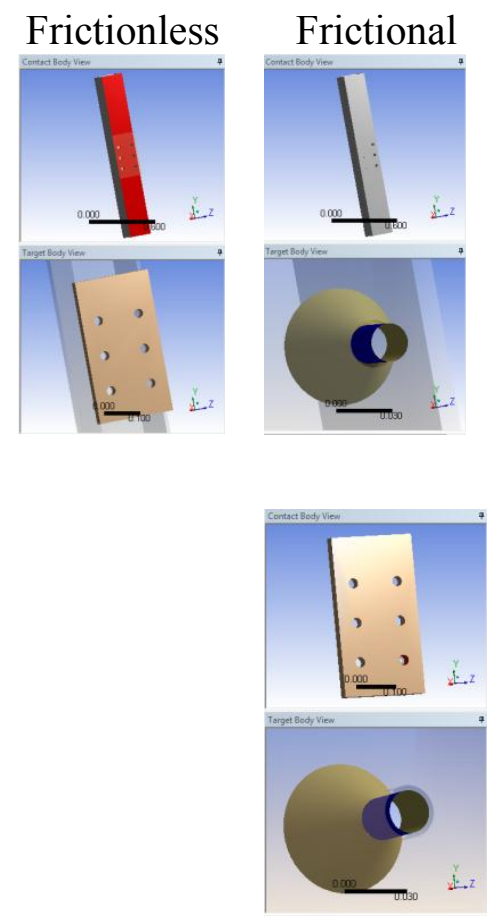

- Bonded: No penetration, separation, or sliding between faces or edges. 
- No separation: similar to bonded, except frictionless sliding can occur along contacting surface.

- Frictionless: No penetration allowed, but surfaces are free to slide and separate without resistance.

- Rough: Similar to frictionless setting except no sliding allowed (i.e. friction coefficient=infinite).

- Frictional: Allows sliding with resistance proportional to user-defined coefficient of friction; free to separate without resistance.

\section{Results and Discussions}

\section{Failure modes}

The observed physical damage and the main response parameters obtained from the analytical tests are presented and discussed in the following sections.

\section{Failure in sleeve}

The failure mode is excessive tensile stresses or failure in the sleeve due to metal forming Wang and Wang, (2016) in addition to Sheet Metal Forming, process and application. Figure 7 shows the stress distribution on the critical bolts.

It is clear that the bolts at tension flange suffer from excessive axial stresses which are transferred into shear stresses on the critical section of the sleeve.

1.
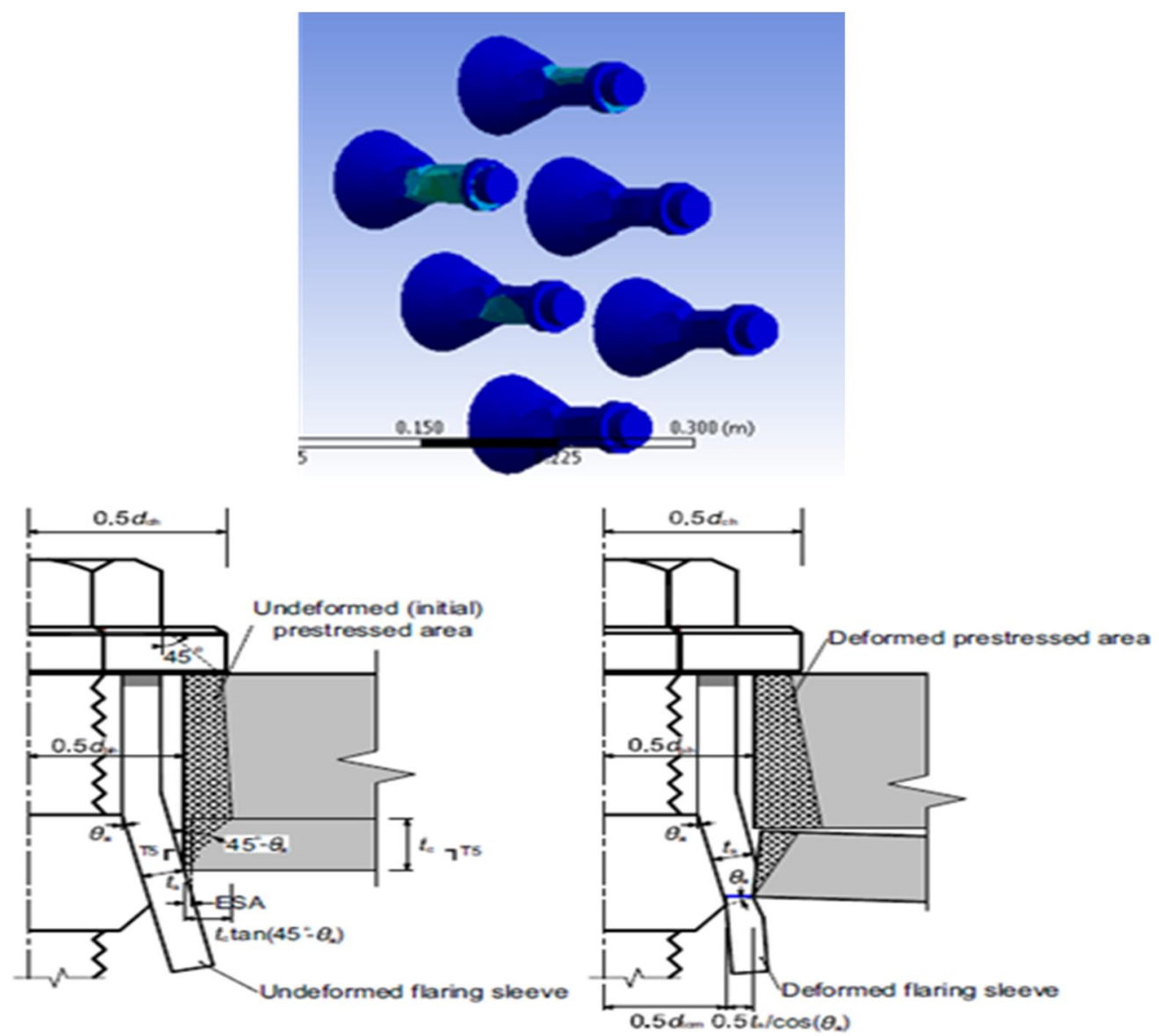

Fig. 7: Stress distribution on bolts and expected failure at sleeve

Figure 8 demonstrates the failure of sleeve as in experimental tests done by Pitrakkos and Tizani, (2013). As shown below, the deforming flaring sleeve is bent due to the axial force on the bolt which is transferred to shear force on the sleeve.

Figure 8 illustrates the phases of failure which are summarized as follows:

1. The first phase is tightening process to ensure full contact between the sleeve outer face and the column inner face. This process is done by tightening the bolt with torque until full tightening is established 
2. The second phase is the phase where the connection is prior to ultimate capacity phase. This deformation can be classified as elastic deformation. In this phase the tensile stresses in sleeve are accompanied by enlargement of the bolt holes of the column.

The third phase is the ultimate phase where the sleeve reaches the ultimate capacity and leads to failure of the connection. This deformation is classified as plastic deformation or irreversible deformation. This failure is usually accompanied by excessive enlargement in the bolt holes in the face of the column.

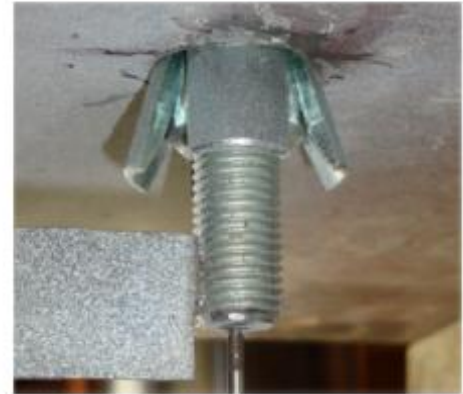

(a) at tightening

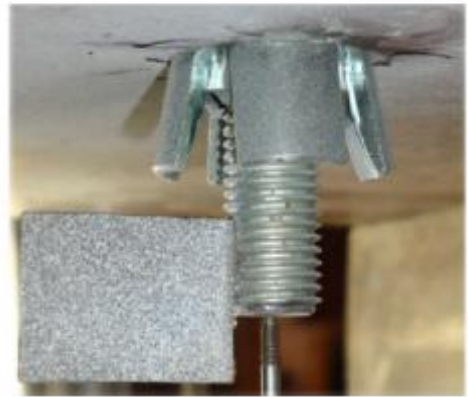

(b) prior to ultimate capacity

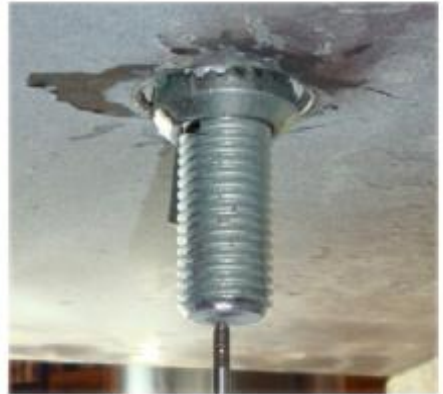

(c) failure

Fig. 8: Failure in sleeve as in experimental tests, (2013)

\section{Failure in bolts}

The bolt and the sleeve are associated together. The tension force in the bolt is transferred as a shear stress on the critical section of the sleeve. The bolt suffers from combined shear and tension stresses due to applied force at the tip of the I-section. As shown below in Figure 9, the bolt at the tension side suffers from tension force due to bending moment in addition to shear force but the significant force is the moment. Both the grade and the diameter of the bolt are the most effective variable in calculating the percentage of contribution of the bolts in the design calculation. As shown in figure 9, the upper two bolts are the only bolts contributing in resisting the normal stresses due to bending. The shear force is resisted by the whole 6 bolts but the shear force on bolts is not the governing force in these types of connection. The edge distance between the bolt and the end of the column is very essential as it affects the rate of enlargement of the tube holes. It is recommended to ensure that the bolt holes at failure is not reaching the edge of the column tube.

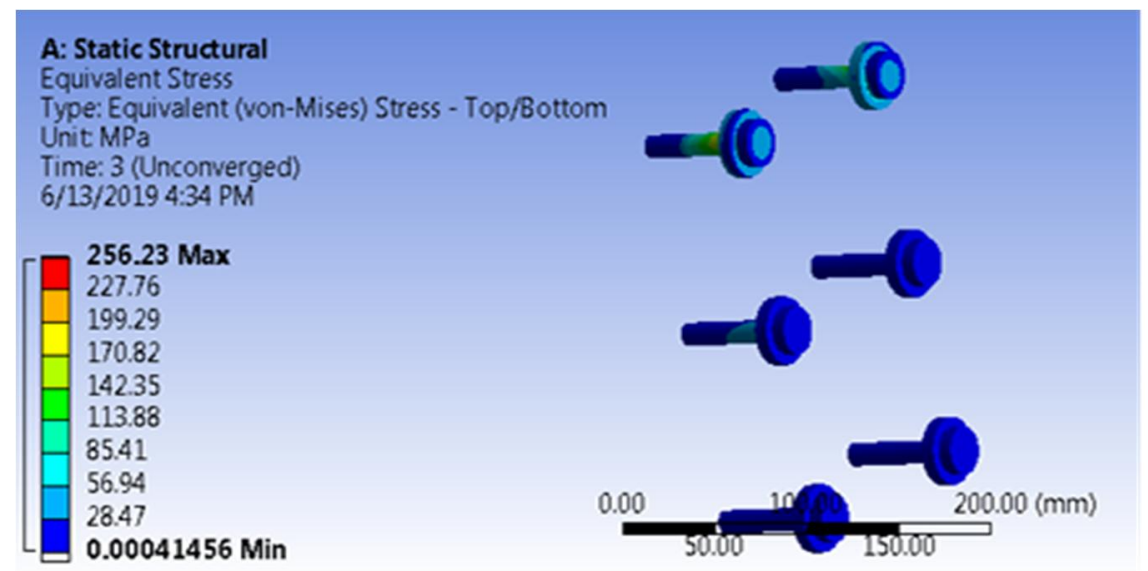

Fig. 9: Bolt's stress distribution

\section{Failure in end plate}

Traditional stress distribution occurs on the endplate according to yield line analysis phenomena due to axial stresses on the connection (moment or axial forces), although it is not a major mode of failure like the bolt sleeve. Figure 10 shows the end plate stress distribution. The thickness of the end plate is affecting the prying force on the critical bolts. Additional tension forces is added to the bolt tension force due to prying forces. 
The holes of the endplate is enlarged as a result of stress concentration of the bolt at bolt hole. The enlargement in bolt holes is directly proportional to the applied force on the connection and inversely proportional to the end plate thickness. However the thickness of end plate is likely to be greater than the tube thickness so the critical section will be the tube thickness at bolt holes. It is not a critical mode of failure at this type of connection as the column face and sleeve thickness are likely to control the modes of failure of the connection. The lower part of the end plate suffers from compression forces. it is affecting the end plate due to bearing of the lower flange of the I section on the outer face of the end plate. The higher the applied force, the higher is bearing force on the end plate.

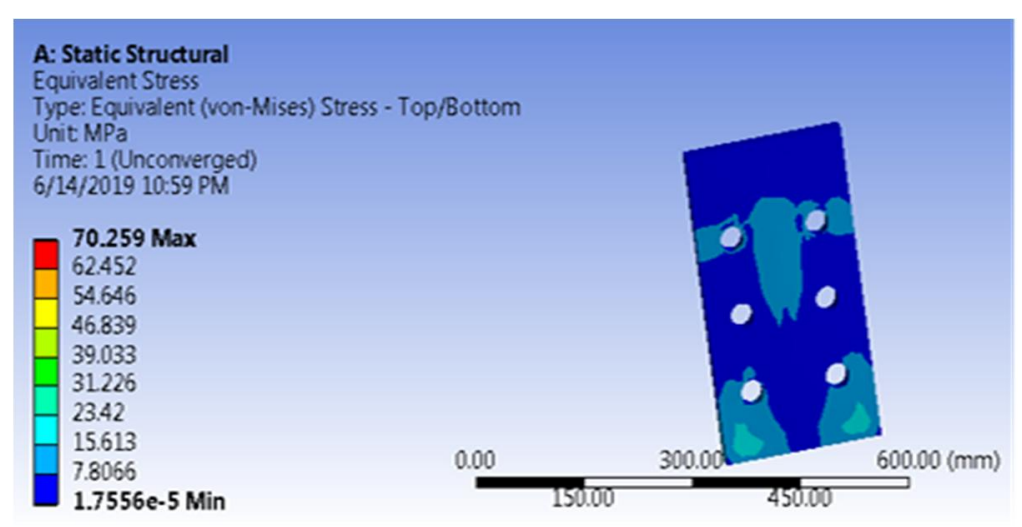

Fig.10: End plate stress distribution

\section{Failure in tube face}

The column is considered as the main point of fixation of the whole connection. It plays a major role in determining whether the connection is rigid enough or flexible. Also the figure shows clearly that the hole in the SHS is enlarged as the forces increased which may be considered as a mode at failure in addition to the stress concentration at location of holes, Mahmood et al., (2014). Figure 11 shows the stress distribution on the face of the square hollow section under the applied load. It is similar to the stress distribution on the end plate but denser. Yield line theory is also demonstrated in the contour lines of stresses reflecting the smooth and fine behaviour of the column face under applying static loading (Elamin, 2014). The enlargement of the tube holes occurs suddenly without any warnings which can be considered as a brittle failure.

A combined mode of failure between the sleeve and the column face can occur due to metal forming which can cause the slippage of the bolt from the hole of the column. One of the main solutions of stiffening the column stiffness is by adding stiffeners inside the tube section or increasing the thickness of the tube locally at connection.
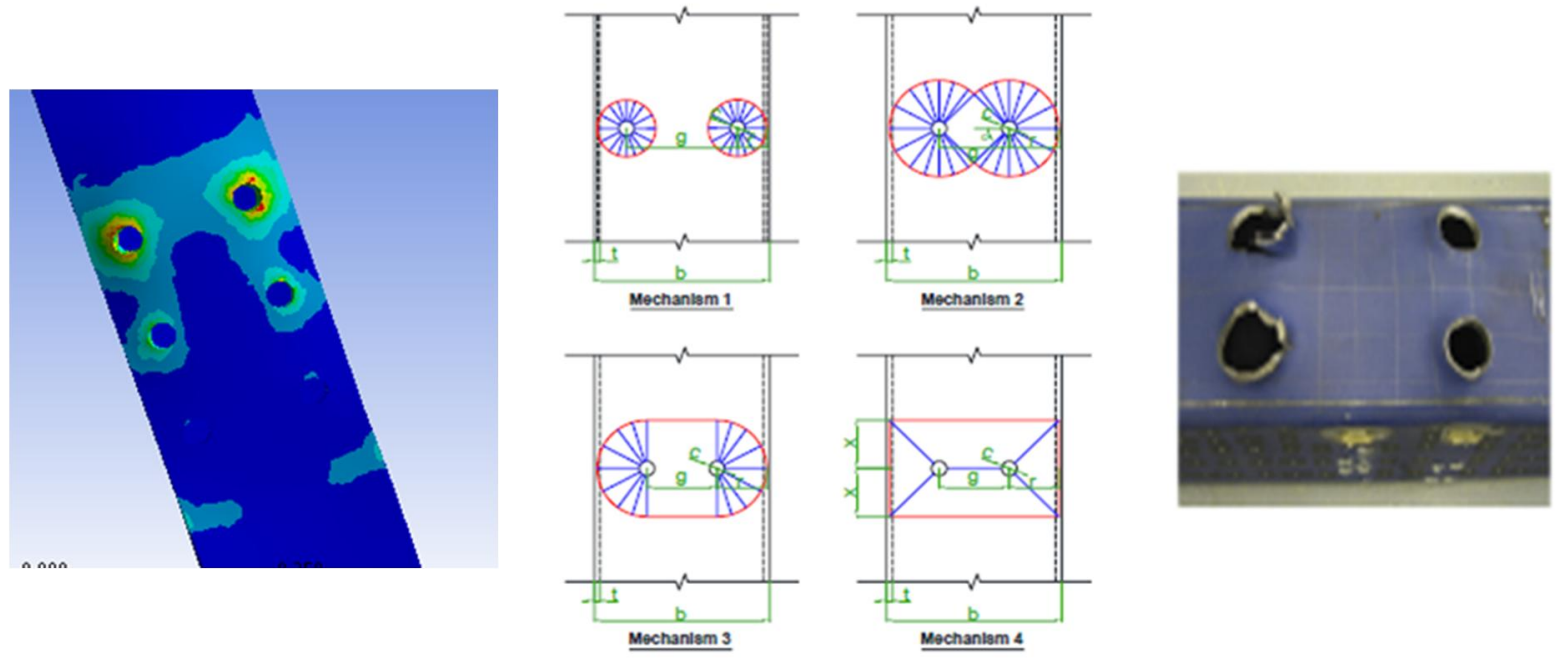

Fig. 11: Stress distribution, bolt hole enlargement at the face of SHS and theoretical yield line theory 
It is observed from the numerical analysis that the critical parts that have stress concentration is the sleeve of the bolts as shown in Figure 7 in addition to the tube face as shown in Figure 11. This illustrates the behaviour of metal forming which occurs to the hole in the square hollow section due to the contact between the hole and the bolt with sleeve.

Metal forming is the metal working process of forming metal parts and objects through mechanical deformation; the work piece is reshaped without adding or removing material, and the mass remains unchanged. Forming causes plastic deformation in the material while the physical shape of a material remains permanently deformed.

\section{Force deflection curves}

A series of graphs is illustrated to show the effect of various parameters on the connection stiffness behaviours and the location of stress concentration in the studied connection. This is to know the critical elements in the connection under static loading presented in the below graphs.
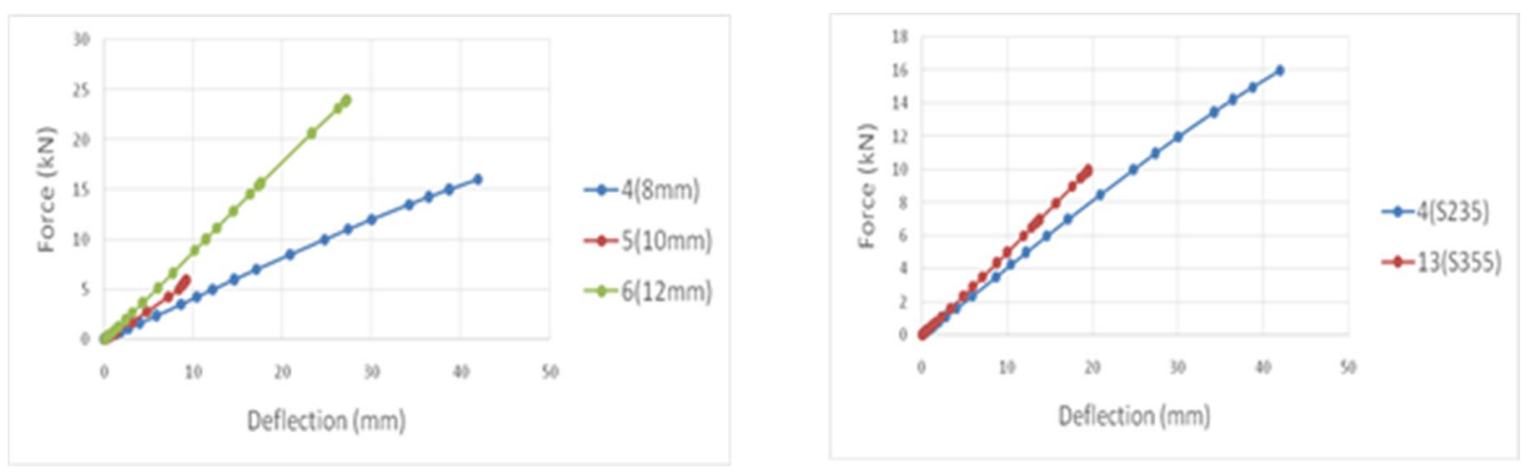

Fig. 12: Graphs showing the effect of SHS thickness and grade on the connection strength under static loading
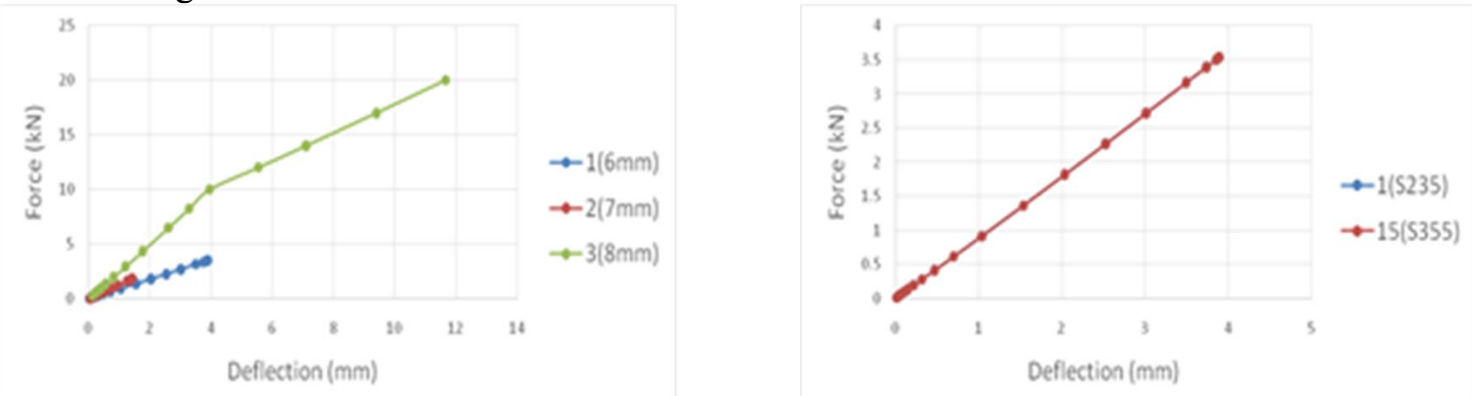

Fig.13: Graphs showing the effect of sleeve thickness and grade on the connection strength under static loading
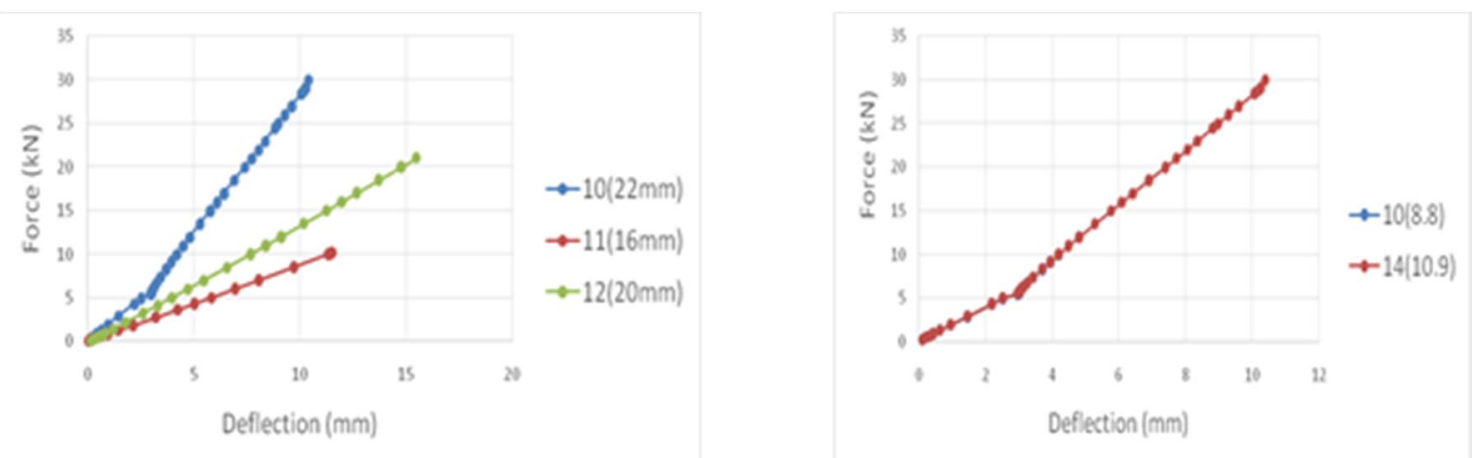

Fig.14: Graphs showing the effect of bolt size and grade on the connection strength under static loading 


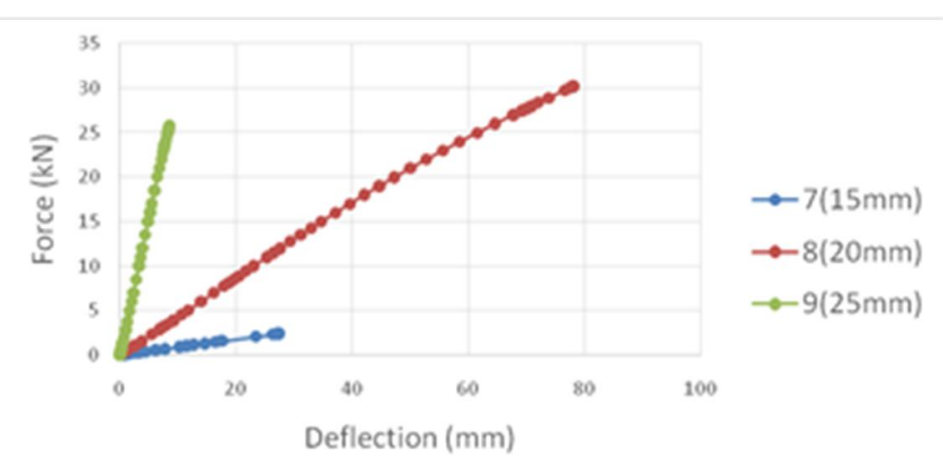

Fig. 15: Graphs showing the effect of end plate thickness on the connection strength under static load

The numerical models observations indicate four representative items which affect the behaviour of the blind bolted connection. Each parameter will be discussed and summarized as below:

\section{The column size and grade}

The column is the main supporting system of the blind connection and affects both the stiffness and the ultimate capacity of the connection. Figure 12 shows the effect of using different column thicknesses under the effect of static loading. Using_column thickness $8 \mathrm{~mm}$ shows that the vertical deflection of the connection at the tip of the cantilever is approximately $43 \mathrm{~mm}$ at a force of $17 \mathrm{kN}$ force at tip of the cantilever, while for column thickness $10 \mathrm{~mm}$ the vertical deflection of the connection at the tip of the cantilever is approximately $10 \mathrm{~mm}$ at a force of $7 \mathrm{kN}$. For column thickness $12 \mathrm{~mm}$ the vertical deflection of the connection at the tip of the cantilever is approximately $27 \mathrm{~mm}$ at force of $24 \mathrm{kN}$. It is clearly shown that the behaviour of the connection is enhanced with increasing the Column thickness with the same outer dimensions.

The steel grade is shown to have a very minor effect on the displacement and stiffness of the connections.

\section{The sleeve thickness and grade}

The sleeve is considered as the most important and critical element in the blind bolted connection. The sleeve experienced a metal forming process. As a result of applying static vertical loads at the tip of cantilever, Figure 13 shows the effect of increasing the sleeve thickness on the behaviour of the connection. When using the $6 \mathrm{~mm}$ sleeve thickness, the deflection at the tip of cantilever is $4 \mathrm{~mm}$ at a force $4 \mathrm{kN}$. When using $7 \mathrm{~mm}$ sleeve thickness, the deflection at the tip of cantilever is $1 \mathrm{~mm}$ at a force $2 \mathrm{kN}$ and finally for $8 \mathrm{~mm}$ sleeve thickness, the deflection at the tip of cantilever is $12 \mathrm{~mm}$ at a force $20 \mathrm{kN}$.

The Steel grade is shown to have a very minor effect on the displacement and stiffness of the connections.

\section{The bolt size and grade}

The bolt is considered as the key element that connects the I section with the SHS column. The bolt is also attached to the sleeve and is considered as the point of fixation of the sleeve when considering the statical system of the sleeve as a cantilever.

Under the effect of static vertical load at the tip of the cantilever, Figure 14 shows the effect of using different bolt sizes on the behaviour of the connection. The $16 \mathrm{~mm}$ bolt size induces $12 \mathrm{~mm}$ deflection at the tip of the cantilever at a force of $10 \mathrm{kN}$. The $20 \mathrm{~mm}$ bolt induces $16 \mathrm{~mm}$ deflection at a force of $21 \mathrm{kN}$ and finally the $20 \mathrm{~mm}$ bolt induces $10 \mathrm{~mm}$ deflection at a force of $30 \mathrm{kN}$. The area under the curve increases with the increase of bolt size.

Steel grade is shown to have a very minor effect on the displacement and stiffness of the connection behaviour.

\section{The end plate thickness}

The end plate is one of the factors that affects the behaviour of the connection in addition to the amount of tensile forces transferred to the bolt and the sleeve. 
Under the effect of static loading, the behaviour is shown to be enhanced by increasing the end plate thickness. Figure 15 shows that the deflection decreases with the increase in the end plate thickness, the $15 \mathrm{~mm}$ end plate induces maximum deflection of $25 \mathrm{~mm}$ at a force of $2.5 \mathrm{kN}$ while the $20 \mathrm{~mm}$ end plate induces $80 \mathrm{~mm}$ at a force of $30 \mathrm{kN}$ and finally the $25 \mathrm{~mm}$ end plate induces $5 \mathrm{~mm}$ deflection at a force of $26 \mathrm{kN}$.

It is clear that when using $25 \mathrm{~mm}$ end plate the stiffness of the connection increases significally and becomes very rigid.

The steel grade is shown to have a very minor effect on the displacement and stiffness of the connection.

\section{Summary and Conclusion}

- The blind bolted connections seem to withstand low straining actions.

- The phenomenon of metal forming is a new mode of failure that needs to be taken into consideration in the design of sleeve thickness.

- The phenomenon of bolt slippage is likely to occur and needs further examinations and studies before depending on these types of blind bolted connections in main structural building.

- Column stiffness is one of the main keys in determining the capacity of the connection and its rigidity. Also, it is a main factor in bolt slippage mode of failure.

- The steel grade has a very minor effect on the stiffness and rigidity of the connections.

- The bolt is attached to the sleeve and is considered as the point of fixation of the sleeve when considering the statical system of the sleeve as a cantilever.

- The end plate affects the tension in the critical bolt due to prying effect which is transferred to the sleeve.

- The moment transferred from the tip of the cantilever depends on all elements of the connection (end plate, bolt, sleeve and supporting column).

- It is not recommended to use blind bolted connections in important buildings.

- The two most efficient procedures to increase the capacity of the connection and its rigidity is to increase the column thickness or increase the sleeve thickness.

\section{Abbreviations}

$\begin{array}{ll}E & \text { Elasticity modulus [MPA] } \\ \mathrm{SHS} & \text { Square Hollow Section } \\ \Theta & \text { Rotational moment of inertia } \\ \varepsilon & \text { Strain } \\ \sigma & \text { Stress } \\ \Delta & \text { Deflection } \\ \mathrm{RMH} & \text { Reverse Mechanism Hollobolt } \\ \mathrm{R}_{\mathrm{m}} & \text { Tensile strength } \\ \mathrm{S}_{\mathrm{f}} & \text { Stress under proof } \\ \mathrm{Rp}_{0.2} & \text { Stress at } 0.2 \% \text { non-proportional elongation, } \\ \mathrm{d} & \text { Diameter } \\ \mathrm{t} & \text { Thickness }\end{array}$

\section{References}

Altan T. A.E. Tekkaya, Sheet Metal Forming, Process and Application,

ANSYS workbench 15.0 software technical manual.

Brian, D. and V.I. Patel, 2015. Behaviour of demountable CFST column-column connections, Centre for Infrastructure Engineering and Safety. 22 Issue 2 Pages.429-448.

DNV-RP C208, 2013. Determination of Structural Capacity by Non-linear FE analysis Methods.

Elamin, A.M., 2014. The face bending behaviour of blind-bolted connections to concrete-filled hollow sections, PHD thesis, University of Nottingham. 
Groux, Y.M. and A. Picard, 1977. Rigid framing connections for the tubular column. Can J Civ Eng., 4:143-54.

ISO 898-1, 2013. Mechanical properties of fasteners made of carbon steel and alloy steel, Part 1; Bolts, Screws, and studs with specific property classes-Coarse thread and fine pitch thread.

Lee, J., H.M. Goldsworthy and E.F. Gad, 2010. Blind bolted T-stub connections to unfilled hollow section columns in low rise structures. Journal of Constructional Steel Research, 66(8-9): 98192.

Lindapter, 2011. Technical Innovation in Steel Connections for blind bolting connection, Technical manual

Mahmood, M., W. Tizani, and C. Sansour, 2014. Effect of Tube Thickness on the Face Bending for Blind-Bolted Connection to Concrete Filled Tubular Structures, world academy of science ,engineering and technology, international journal of civil and environmental engineering, Vol:8 No:9.

Mashaly, E., M. El-Heweity, H. Abou-Elfath, and M. Osman, 2011. Finite element analysis of beamto-column joints in steel frames under cyclic loading, Alexandria engineering journal,50(1),91104.

Pitrakkos, T. and W. Tizani, 2013. Experimental behaviour of a novel anchored blind-bolt in tension, engineering structure journal, 49,905-919.

Rao, D.V.P., Kumar and S.R.S., 2006. RHS beam-to-column connection with web openingparametric study and design guidelines. Journal of Constructional Steel Research; 62(8):73946.

Tizani, W., Z.Y. Wang, and I. Hajirasouliha, 2013. Hysteretic performance of a new blind bolted connection to concrete filled columns under cyclic loading: An experimental investigation, engineering structure journal.46, 535-546.

Wang, J.F. and N. Zhang, 2017. Performance of circular CFST column to steel beam joints with blind bolts, Journal of Constructional Steel Research, 130:36-52.

Wang, J. and N. Zhang, 2017. Performance of circular CFST column to steel beam joints with blind bolt, Journal of constructional steel research. 130, 36-52.

Wang, J.F. and B.F. Jr. Spencer, 2013. Experimental and analytical behaviour of blind bolted moment connections, Journal of constructional steel research. , 82, 33-47.

Wang, Z.Y. and Q.Y. Wang, 2016. Yield and ultimate strengths determination of a blind bolted endplate connection to square hollow section column, engineering structure journal, advances in structural engineering and mechanics (ASEm15),111,345-369.

White, R.N., and P.J. Fang, 1966. Framing connections for square structural tubing. J Struct Division, Am Soc Civil Eng Proc., 92(ST2):175-94. 